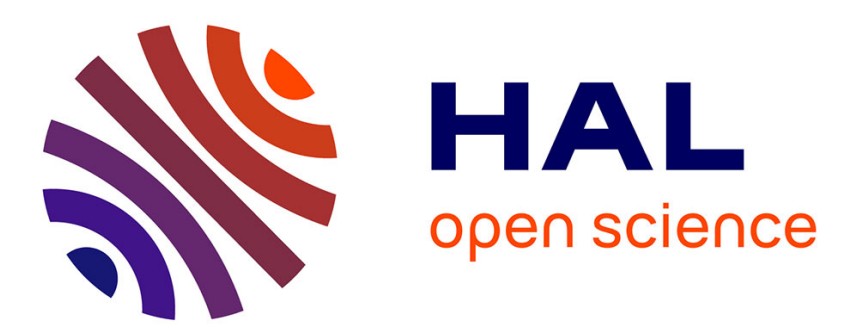

\title{
Characterization of a 8-Ports Vector Antenna for Measurement Applications
}

\author{
Christophe Morlaas, Johan Duplouy, Alexandre Chabory
}

\section{To cite this version:}

Christophe Morlaas, Johan Duplouy, Alexandre Chabory. Characterization of a 8-Ports Vector Antenna for Measurement Applications. CAMA 2019, IEEE International Conference on Antenna Measurements and Applications, Oct 2019, Kuta, Indonesia. 10.1109/CAMA47423.2019.8959555 . hal02456167

\section{HAL Id: hal-02456167 \\ https://hal-enac.archives-ouvertes.fr/hal-02456167}

Submitted on 27 Jan 2020

HAL is a multi-disciplinary open access archive for the deposit and dissemination of scientific research documents, whether they are published or not. The documents may come from teaching and research institutions in France or abroad, or from public or private research centers.
L'archive ouverte pluridisciplinaire HAL, est destinée au dépôt et à la diffusion de documents scientifiques de niveau recherche, publiés ou non, émanant des établissements d'enseignement et de recherche français ou étrangers, des laboratoires publics ou privés. 


\title{
Characterization of a 8-Ports Vector Antenna for Measurement Applications
}

\author{
C. Morlaas*, J. Duplouy*, A. Chabory* \\ *ENAC, Universit de Toulouse, France, Email: christophe.morlaas@enac.fr
}

\begin{abstract}
A wideband and radiation-pattern-reconfigurable vector antenna that presents eight ports is characterized for antenna measurement applications. This vector antenna can be advantageously employed either as a multi-polarized probe in a classical measurement set-up or as a reference antenna in a multi-probe antenna system with the test-zone-field (TZF) compensation method. Thank to the capability of polarization diversity inherent to vector antennas and to the radiation pattern reconfigurability of the proposed antenna, the complexity and time of the measurement process can be reduced.
\end{abstract}

\section{INTRODUCTION}

During past decades, some efforts have been carried out to develop methods to improve the accuracy in radiation antenna measurement. Even in anechoic conditions the antenna under test (AUT) is affected by his surrounding environment. The $\mathrm{TZF}$ is impacted by interfering fields due to scattering or reflection in the surrounding environments including conducting wires and probe antenna (PA). Correction methods tend to reduce the environment effects on measure results by removing the spirious fields from calibration measurements [1]-[3] at the cost of a complicate process and time-consuming. Fig. 1 illustrates a typical measurement set-up.

Certain methods can theoretically be used for measurement in an open environment without anechoic chamber and absorbent materials, like for example, the TZF compensation technique [4], [5] using a reference antenna (RA). Moreover, it is applicable to different measurement types like farfield, compact chamber, and near-field range. The most of techniques imply to initially know the radiation pattern of the PA while in the techniques, only the RA needs to be known since the PA is included in the TZF measurement. Then, it is attractive for multi-probe antenna measurement systems [6]. Nevertheless, this method is based on the spherical harmonic expansion of the electromagnetic field (EM) and involve the RA is bigger than the AUT to be able to measure a sufficient number of spherical harmonics. Then, the measurement process is timeconsuming since the cross-polarization must also be evaluated by rotating the PA or the RA.

In this paper we present a multi-antenna probe (firstly designed for electromagnetic field direction of arrival (DOA) estimation [7] as a vector antenna) for antenna measurement applications such as the TFZ compensation method. This vector antenna (VA) presents some diversity properties, in polarization, and radiation pattern on a wide-band frequency range. Also, a VA can advantageously be used as a PA to reduce the set-up complexity and measurement time since

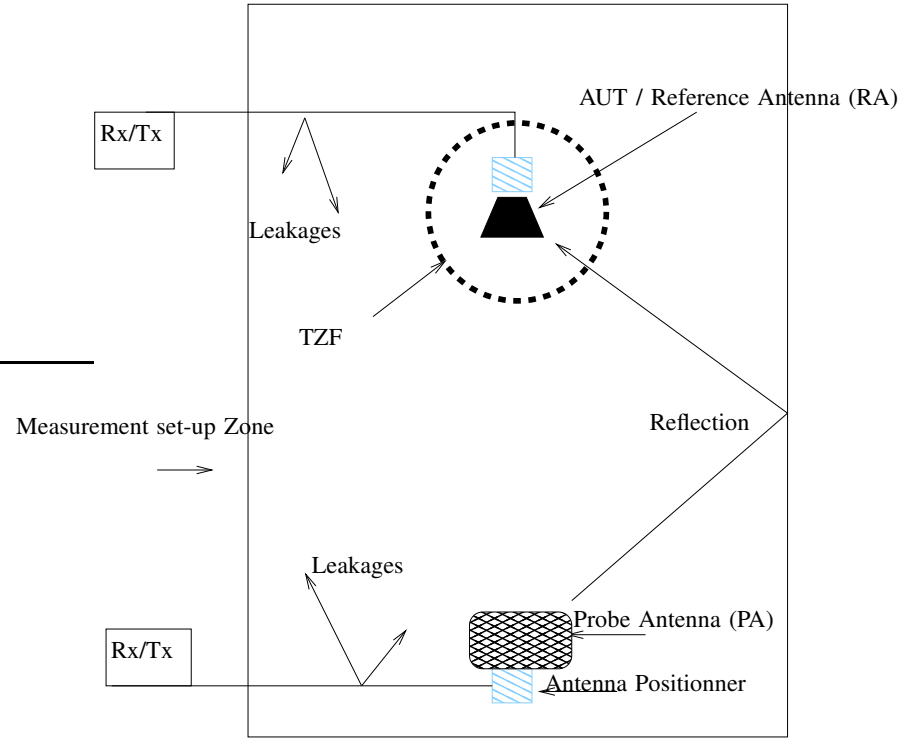

Fig. 1. Measurement set-up

less rotations are required. As mentioned in [6], the orthogonality properties on the radiation pattern is an advantage to increase the channel response diversity and hence to reduce the measurement sensitivity to noise. Furthermore, the number of measurement angles could be reduced by mean the capability of the radiation pattern reconfigurability.

The antenna is first presented in section II. Then, in section III the radiation characteristics and the reconfigurability capability are studied.

\section{ANTENNA PRESENTATION}

The antenna proposed in [7], [8] is first improved in terms of impedance bandwidth optimizing the microstrip-lines dimensions. This VA is represented in Fig. 2. It is composed of two orthogonal and collocated vertical semi-circular arrays of Vivaldi antennas (VSA) above an horizontal array of scaled Vivaldi antennas (HSA) acting as a metallic-shaped ground plane for the vertical elements.

Each VSA contains four Vivaldi antennas with a dual-port feeding by means of microstrip to slotline transitions. Each microstrip-to-slot transition is ended by a circular cavity of radius $5.5 \mathrm{~mm}$ and a $80^{\circ}$ radial stub of radius $5.5 \mathrm{~mm}$. The metallic-shaped ground plane is an horizontal array of eight Vivaldi antennas with a scaled-up size of 1.5 compared to the dimension of the vertical Vivaldi antenna arrays except 


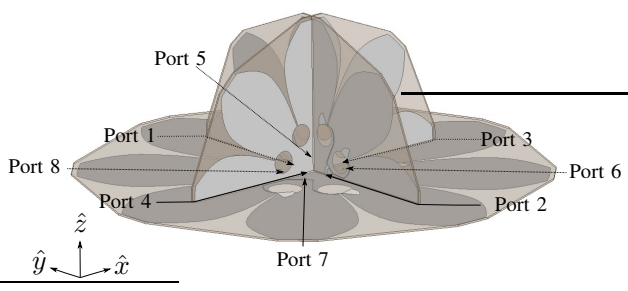

(a)

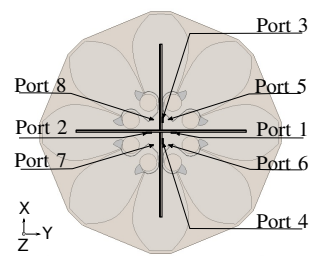

(b)

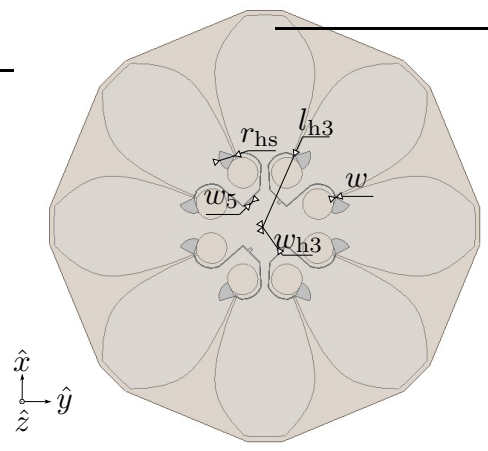

(c)

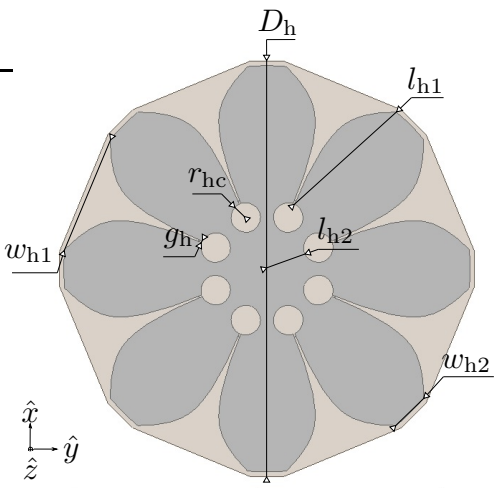

(d)

Fig. 2. Antenna presentation. Geometry (a) and top view (b) of the multi-port VA. Top (c) and bottom (d) views of the VA.

for the widths of the microstrip lines $\left(w_{4}\right.$ and $\left.w_{5}\right)$ and the thickness of the FR4 dielectric substrate $(0.8 \mathrm{~mm})$. One port feeds two antenna elements so that four ports are used to feed the horizontal radiating elements. Finally, the multi-ports antenna includes 8 ports. The dimensions of the HSA elements are reported in Table I and represented in Fig. 2.

TABLE I

DIMENSIONS OF THE HSA

\begin{tabular}{c|cccccc}
\hline Parameter & $D_{\mathrm{h}}$ & $l_{\mathrm{h} 1}$ & $l_{\mathrm{h} 2}$ & $l_{\mathrm{h} 3}$ & $w_{\mathrm{h} 1}$ & $w_{\mathrm{h} 2}$ \\
Values (in mm) & 230 & 75.75 & 22.5 & 40.6 & 65.7 & 21.6 \\
Parameter & $w_{\mathrm{h} 3}$ & $g_{\mathrm{h}}$ & $r_{\mathrm{hc}}$ & $r_{\mathrm{hs}}$ & $w_{4}$ & $w_{5}$ \\
Values (in mm) & 13.9 & 0.9 & 8.25 & 8.25 & 0.36 & 1.58 \\
\hline
\end{tabular}

\section{ANTENNA CHARACTERISTICS}

\section{A. Impedance bandwidth}

The voltage standing wave ratio (VSWR) from $S_{i i}$ parameters corresponding to the vertical $\left(S_{11}\right)$ and horizontal elements $\left(S_{55}\right)$ are plotted in Fig. 3. For symmetry reasons, only measurements for one vertical (V) and one horizontal (H) ports are plotted. The total bandwidth at VSWR $\leqslant 2.3$ is about $6.8: 1(1.24 \mathrm{GHz}$ to $8.4 \mathrm{GHz})$.

The $S_{i j}$ parameters corresponding to the vertical $\left(S_{i j}^{V V}\right)$, vertical to horizontal $\left(S_{i j}^{V H}\right)$ and horizontal $\left(S_{i j}^{H H}\right)$ coupling are plotted in Fig. 4. It can be observed that the isolation between ports are smaller than $-20 \mathrm{~dB}$ for frequencies above $2 \mathrm{GHz}$ regardless of the combination between the vertical and horizontal ports.

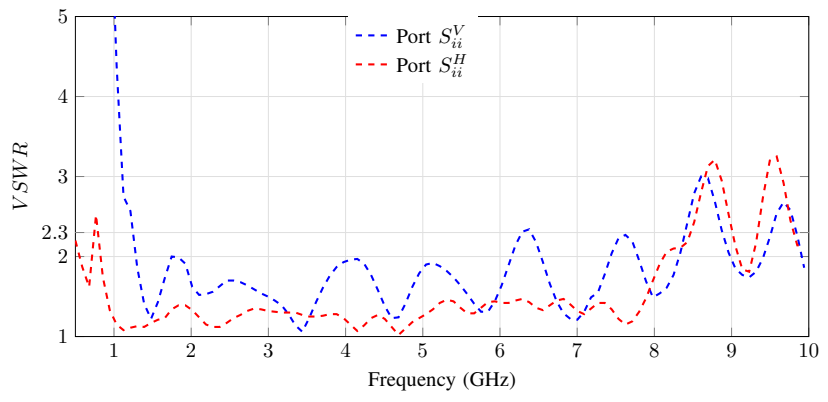

Fig. 3. Measured VSWR of the multi-ports VA as a function of frequency.

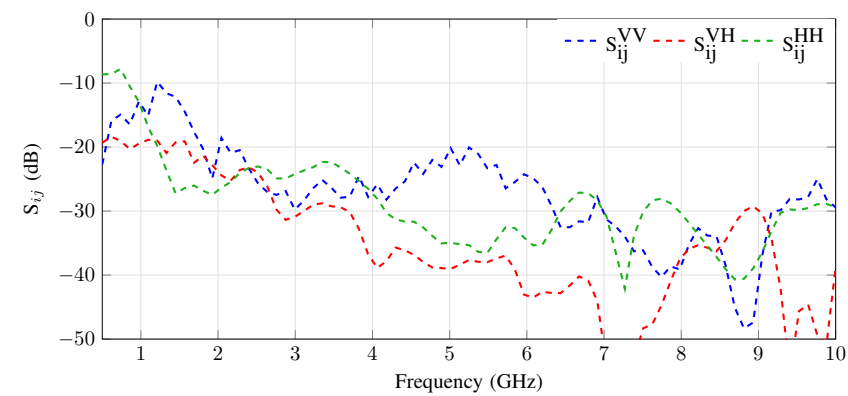

Fig. 4. Measured isolation between the horizontal $(\mathrm{H})$ or/and vertical (V) ports of the the multi-ports VA according to frequency. Only the poorest (i.e., worst-case) mutual couplings $\mathrm{S}_{i j}$ are plotted.

\section{B. Radiation pattern diversity}

According to the weight applied to each port, a specific radiation pattern is radiated. Table II provides the set of weighting coefficients allowing to synthesize the main orthogonal radiation patterns.

radiation patterns for some feeding states are depicted in Table II and plotted in Fig. 5 and Fig. 6. When the AUT is oriented toward the $\mathrm{z}$-axis, the VA enables to generate 
TABLE II

SET OF WEIGHTING COEFFICIENTS ASSIGNED TO THE SIGNALS RECEIVED AT THE 8 PORTS OF THE VA FOR ORTHOGONAL DIPOLE SYNTHESIS.

\begin{tabular}{ccccc|cccc} 
Radiation & \multicolumn{4}{c}{ VSA Ports } & \multicolumn{4}{c}{ HSA Ports } \\
pattern & 1 & 2 & 3 & 4 & 5 & 6 & 7 & 8 \\
\hline$x$-Mag. dipole & 1 & -1 & 0 & 0 & 0 & 0 & 0 & 0 \\
$y$-Mag. dipole & 0 & 0 & 1 & -1 & 0 & 0 & 0 & 0 \\
$z$-Elec. dipole & 1 & 1 & 1 & 1 & 0 & 0 & 0 & 0 \\
$x$-Elec. dipole & 0 & 0 & 0 & 0 & 1 & -1 & -1 & 1 \\
$y$-Elec. dipole & 0 & 0 & 0 & 0 & 1 & 1 & -1 & -1 \\
$z$-Mag. dipole & 0 & 0 & 0 & 0 & 1 & -1 & 1 & -1 \\
\hline
\end{tabular}

four radiation patterns in orthogonal polarization. When the VSA along the $y$-axis is fed with the $1^{\text {st }}$ line of Table II, it allows to synthesize the radiation pattern of a magnetic dipole (Mag.Dip.) along the x-axis (Fig. 5-(b) \& Fig. 6-(b)). The corresponding orthogonal polarization is obtained when the $2^{\text {nd }}$ line of Table II is used for feeding the antenna. As well, when the HSA is supplied with the $4^{\text {th }}$ line of Table II, it allows to synthesize the radiation pattern of an electrical dipole (Elec.Dip.) along 0x-axis (Fig. 5-(a) \& Fig. 6-(a)) and the corresponding orthogonal polarization when the $5^{\text {th }}$ line is used.

The $x$-Mag.Dip. and the $y$-Mag.Dip. generate two radiation patterns of orthogonal polarization along the $0 z$ direction. Consequently, this multi-PA can be used classically to measure the AUT reducing the process-time by two since it is no more necessary to rotate it to generate the two orthogonal polarizations for each measured point as well as when the $x$-Elec.Dip. and $y$-Elec.Dip. Moreover, adequate signal processing can advantageously be performed using this diversity to obtain more accurate environment calibration through a RA measurement.

This VA could also be used as a RA in the TZF compensation method. Indeed, the number of rotations required to scan the radiation pattern can be greatly reduced using the 8-ports antenna as RA. For instance, eight-rotating radiation patterns around the $z$-axis (each $45^{\circ}$ ) are obtained without moving the antenna by applying the feeding weight reported in Table III on only the VSA ports ( 1 to 4 ). In this case, only $\theta$-polarization fields are obtained. To generate the orthogonal polarization, the HSA ports (5 to 8 ) can be supplied as reported in Table III.

A $\phi=45^{\circ}$ radiation pattern in $\theta$-polarization (a) and $\phi$-polarization (b) is plotted in Fig. 7 at $3.4 \mathrm{GHz}$. This radiation pattern is the same rotated in $45^{\circ}$ for other weighting coefficients. Its are stable until $3.4 \mathrm{GHz}$ after that, some ripples appears considering the antenna size that increases compare to the wavelength.

Other weighting coefficient combinations can be applied to electronically scan the radiation pattern angles without rotating the antenna.
TABLE III

SET OF WEIGHTING COEFFICIENTS ASSIGNED TO THE SIGNALS RECEIVED FOR $z$-AXIS RADIATION PATTERN ROTATION IN $\theta$ AND $\phi$-POLARIZATION.

\begin{tabular}{ccccc|cccc} 
Rotation & \multicolumn{4}{c}{ VSA Ports } & \multicolumn{4}{c}{ HSA Ports } \\
angle $\phi$ & 1 & 2 & 3 & 4 & 5 & 6 & 7 & 8 \\
\hline $0^{\circ}$ & 0 & 0 & 1 & 0 & 1 & 0 & 0 & -1 \\
$45^{\circ}$ & 1 & 0 & 1 & 0 & 1 & 0 & 0 & 0 \\
$90^{\circ}$ & 1 & 0 & 0 & 0 & 1 & -1 & 0 & 0 \\
$135^{\circ}$ & 1 & 0 & 0 & 1 & 0 & 1 & 0 & 0 \\
$180^{\circ}$ & 0 & 0 & 0 & 1 & 0 & 1 & -1 & 0 \\
$225^{\circ}$ & 0 & 1 & 0 & 1 & 0 & 0 & 1 & 0 \\
$270^{\circ}$ & 0 & 1 & 0 & 0 & 0 & 0 & 1 & -1 \\
$315^{\circ}$ & 0 & 1 & 1 & 0 & 0 & 0 & 0 & 1 \\
\hline
\end{tabular}

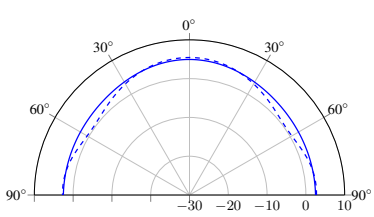

(a) $x$-Elec. Dip., H-plane

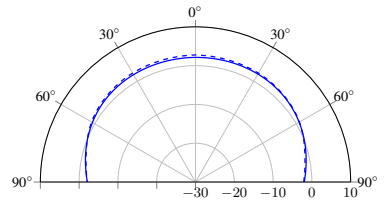

(b) $x$-Mag. Dip., E-plane
Fig. 5. Measured (dashed line) and simulated (solid line) realized gain (dBi) in $\phi$-polarization (a) and $\theta$-polarization (b) at $1.4 \mathrm{GHz}$ in the $\hat{y} z$-plane. Sets of weighting coefficients are specified in Table II for measuring the Elec. and Mag. dipole along $0 x$.

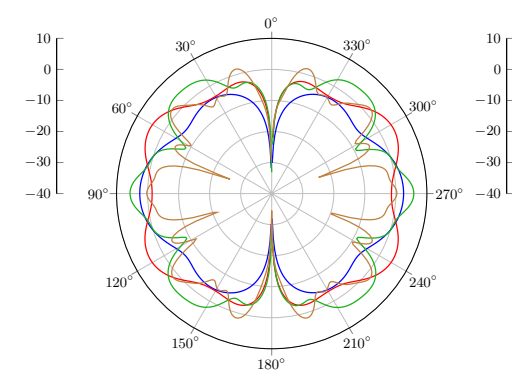

(a) $x$-Elec. Dip., E-plane

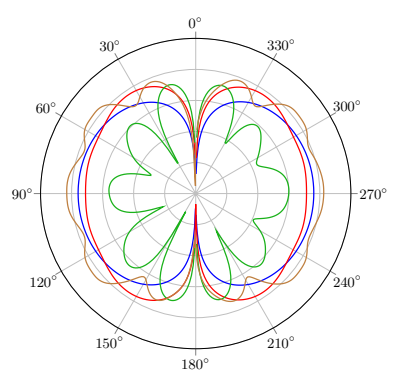

(b) $x$-Mag. Dip., H-plane
Fig. 6. Simulated realized gain ( $\mathrm{dBi})$ in $\phi$-polarization (a) and $\theta$-polarization (b) at $1.4 \mathrm{GHz}$ (blue line), $2.8 \mathrm{GHz}$ (red line), $5 \mathrm{GHz}$ (green line) and $8 \mathrm{GHz}$ (brown line) in the $\hat{x y}$-plane. Sets of weighting coefficients are specified in Table II for measuring the Elec. and Mag. dipole along $0 x$

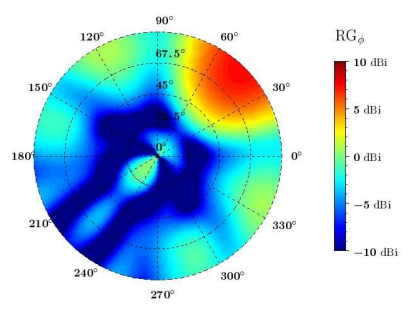

(a) $\phi$-Polar

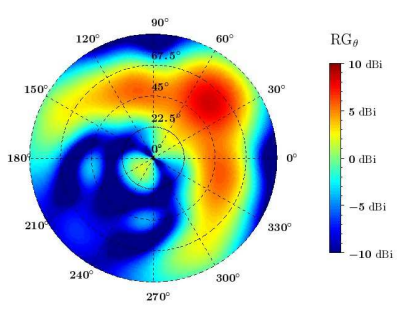

(b) $\theta$-Polar
Fig. 7. Simulated realized gain ( $\mathrm{dBi}$ ) in $\theta$-polarization (a) and $\phi$-polarization (b) at $3.4 \mathrm{GHz}$ in a upper half-sphere. Sets of weighting coefficients defined by $\mathrm{VSA}=[1010]$ and $\mathrm{HSA}=[1000]$, respectively. at $3.4 \mathrm{GHz}$ in a upper halfsphere.

\section{CONCLUSION}

A vector antenna has been proposed for antenna measurement techniques like the TZF method. By mean of this radia- 
tion pattern reconfigurabilty, this antenna seems to be attractive for reducing the duration of the measurement process. This antenna exhibits a total bandwidth VSWR $\leqslant 2.3$ of about 6.8:1 (1.24 GHz to $8.4 \mathrm{GHz})$ and an isolation coefficient smaller than $-20 \mathrm{~dB}$ for frequencies above $2 \mathrm{GHz}$ regardless of the radiation pattern combination between the vertical and horizontal ports. The spherical harmonic number has to be estimated versus the frequency.

\section{REFERENCES}

[1] J. Appel-Hansen, "Reflectivity level of radio anechoic chambers," IEEE Transactions on Antennas and Propagation, vol. 21, no. 4, pp. 490-498, 1973.

[2] D. A. Leatherwood and E. B. Joy, "Plane wave, pattern subtraction, range compensation," IEEE Transactions on Antennas and Propagation, vol. 49, no. 12, pp. 1843-1851, 2001.

[3] V. Viikari, J. Hakli, J. Ala-Laurinaho, J. Mallat, and A. Raisanen, "A feed scanning based apc technique for compact antenna test ranges," IEEE transactions on antennas and propagation, vol. 53, no. 10, pp. 31603165, 2005.

[4] D. N. Black and E. Joy, "Test zone field compensation," IEEE Transactions on Antennas and Propagation, vol. 43, no. 4, pp. 362-368, 1995.

[5] J. T. Toivanen, T. A. Laitinen, and P. Vainikainen, "Modified test zone field compensation for small-antenna measurements," IEEE Transactions on Antennas and Propagation, vol. 58, no. 11, pp. 3471-3479, 2010.

[6] J. T. Toivanen, T. A. Laitinen, S. Pivnenko, and L. Nyberg, "Calibration of multi-probe antenna measurement system using test zone field compensation," in 2009 3rd European Conference on Antennas and Propagation. IEEE, 2009, pp. 2916-2920.

[7] J. Duplouy, C. Morlaas, H. Aubert, P. Potier, P. Pouliguen, and C. Djoma, "Reconfigurable grounded vector antenna for 3-d electromagnetic direction-finding applications," IEEE Antennas and Wireless Propagation Letters, vol. 17, no. 2, pp. 197-200, 2018.

[8] J. Duplouy, C. Morlaas, H. Aubert, P. Potier, and P. Pouliguen, "Wideband and reconfigurable vector antenna using radiation pattern diversity for 3d direction-of-arrival estimation," IEEE Transactions on Antennas and Propagation, early access, 2019. 